Supporting Information

\title{
Electron Transport Layers Based on Oligo(ethylene glycol)- Incorporated Polymers Enabling Reproducible Fabrication of High-Performance Organic Solar Cells
}

Seungjin Lee, Youngwoong Kim, Donguk Kim, Dahyun Jeong, Geon-U Kim, Jinseck Kim, Bumjoon J. Kim*

Department of Chemical and Biomolecular Engineering, Korea Advanced Institute of Science and Technology (KAIST), Daejeon 34141, Republic of Korea

*E-mail: bumjoonkim@kaist.ac.kr (B.J.K.)

KEYWORDS: electron transport layer, organic solar cells, oligo(ethylene glycol), eco-friendly processing, surface tension, storage stability 


\section{Table of Contents}

\section{Experimental Section}

Characterization.

\section{Supplementary Figures}

Scheme S1. Synthetic routes for P(NDIDEG-T) and P(NDITEG-T) polymers.

Figure S1. ${ }^{1} \mathrm{H}$ NMR spectrum of $\mathrm{P}(\mathrm{NDIDEG}-\mathrm{T})$ polymer.

Figure S2. ${ }^{1} \mathrm{H}$ NMR spectrum of P(NDITEG-T) polymer.

Figure S3. Absorption coefficients of P(NDIDEG-T) and P(NDITEG-T) polymers.

Figure S4. CV curves of P(NDIDEG-T) and P(NDITEG-T) polymers.

Figure S5. DSC thermograms of P(NDIDEG-T) and P(NDITEG-T) polymers.

Figure S6. (a) Experimental set-up for the conductivity measurements and the corresponding equations. (b) Plot of resistance as a function of ETL thickness, and the linear-fitted equations for P(NDIDEG-T) and P(NDITEG-T).

Figure S7. $J-V$ curves of electron-only devices based on P(NDIDEG-T) and P(NDITEG-T).

Figure S8. $(\mathrm{a}, \mathrm{b}, \mathrm{c}) \mathrm{UV}-\mathrm{V}$ is absorption spectra of $\mathrm{P}(\mathrm{NDIDEG}-\mathrm{T}), \mathrm{P}(\mathrm{NDITEG}-\mathrm{T})$, and PFN-Br films with various thicknesses. (d, e, f) Extrapolation lines constructed from the absorptionthickness relationship of each ETL film.

\section{Supplementary Tables}

Table S1. Melting temperature $\left(T_{\mathrm{m}}\right)$, crystallization temperature $\left(T_{\mathrm{c}}\right)$, and melting enthalpy $\left(\Delta H_{\mathrm{m}}\right)$ of $\mathrm{P}(\mathrm{NDIDEG}-\mathrm{T})$ and $\mathrm{P}(\mathrm{NDITEG}-\mathrm{T})$ polymers.

Table S2. Crystalline properties of P(NDIDEG-T) and P(NDITEG-T) polymer films obtained from the GIXS measurements.

Table S3. Electron mobility $\left(\mu_{\mathrm{e}}\right)$ values of the $\mathrm{P}(\mathrm{NDIDEG}-\mathrm{T})$ and $\mathrm{P}(\mathrm{NDITEG}-\mathrm{T})$ pristine films. 


\section{Experimental Section}

Characterization. Bruker Advance III HD $500 \mathrm{MHz}$ instrument was used for the ${ }^{1} \mathrm{H}$ NMR analyses. Deuterated chloroform was used as the solvent for the NMR experiment. The number-average molecular weight $\left(M_{\mathrm{n}}\right)$ and dispersity $(\bigoplus)$ of the electron transporting layer (ETL) polymers were measured using the size-exclusion chromatography (SEC) relative to polystyrene standards (Agilent GPC 1200 series with a refractive index detector). For the SEC measurement, $o$-dichlorobenzene $\left(80^{\circ} \mathrm{C}\right)$ was used as the eluent. Cyclic voltammetry $(\mathrm{CV})$ experiments were performed at room temperature with a VSP potientiostat system (BioLogic) and EC-Lab software (scan rate: $50 \mathrm{mV} \mathrm{s}^{-1}$ ). For the $\mathrm{CV}$ measurements, the ETL polymers were dissolved in $N, N$-dimethylformamide (DMF) $\left(2.5 \mathrm{mg} \mathrm{mL}^{-1}\right)$. Note that the $\mathrm{CV}$ measurements were performed in solution state instead of thin-film state to prevent delamination of the ETL films by a polar solvent (e.g., acetonitrile). Tetrabutylammonium tetrafluoroborate $\left(\mathrm{Bu}_{4} \mathrm{NBF}_{4}\right)$ in $\mathrm{DMF}(0.1 \mathrm{M})$ was utilized as the electrolyte. A typical threeelectrode configuration (counter electrode: platinum wire, working electrode: platinum electrode, reference electrode: $\mathrm{Ag} / \mathrm{Ag}^{+}$electrode, where the $\mathrm{Ag}$ wire was dipped into a silver nitrate solution of $0.1 \mathrm{M}$ ) was employed. A UV photoelectron spectrometer (Sigma Probe) was used for the ultraviolet photoelectron spectroscopy (UPS) measurements. He I (21.2 eV) radiation line originated from a discharge lamp was used to determine the work function of bare Ag and ETL-treated Ag electrodes. The UPS samples were prepared by depositing the ETLs onto Ag/glass substrates. Differential scanning calorimetry (DSC) measurements were performed using PerkinElmer DSC 4000. The DSC curves were obtained from the second heating/cooling cycle of the $\mathrm{P}(\mathrm{NDIDEG}-\mathrm{T})$ and $\mathrm{P}(\mathrm{NDITEG}-\mathrm{T})$ polymers with a temperature range of 25 to $275^{\circ} \mathrm{C}$ and a scan rate of $10{ }^{\circ} \mathrm{C} \mathrm{min}^{-1}$. UV-vis absorption spectra were obtained in a thin-film state using a Shimadzu Scientific Instruments UV-1800 spectrophotometer, in which the films were spin-cast from a water/ethanol solution (mole ratio of 
water:ethanol=36:64). The atomic force microscopy (AFM) height images in Figure 5 were acquired using a MultiMode 8 system (Bruker) in the ScanAsyst mode under ambient conditions, whereas the thickness measurement by AFM in Figure S8 was performed using an NX10 (Park Systems) model in the non-contact mode under ambient conditions. Optical microscopy (OM) images were obtained using an upright microscope (Ni-U, Nikon).

Grazing incidence X-ray scattering (GIXS) measurements were conducted at beamline 9A (Pohang Accelerator Laboratory, South Korea). For the GIXS measurements, the ETL solution were spin-cast onto $\mathrm{Si}$ substrates using water/ethanol solvent (mole ratio of water:ethanol=36:64) and the wavelength and the incident angle of the X-rays were $1.119 \AA$ and $\sim 0.12^{\circ}$, respectively. The Scherrer equation was used to estimate the $L_{\mathrm{c}}$ values:

$$
L_{\mathrm{c}}=\frac{2 \pi K}{\Delta_{q}}
$$

where $\Delta_{q}$ is the full width at half maximum of the scatterings and $K$ is the shape factor with a value of 0.9 .

The electron mobilities of the ETLs were measured by the space-charge-limited current (SCLC) method using devices with an electron-only architecture (ITO/ZnO/ETL/LiF/Al). The thickness of the polymer films was determined to be $30 \mathrm{~nm}$. Current-voltage measurements were performed in the voltage range of $0-8 \mathrm{~V}$ and the results were fitted by the Mott-Gurney equation:

$$
J_{\mathrm{SCLC}}=\frac{9}{8} \varepsilon \varepsilon_{0} \mu \frac{V^{2}}{L^{3}}
$$

in which $\varepsilon$ is the relative dielectric constant of the ETL, $\varepsilon_{0}$ is the permittivity of free space $\left(8.85 \times 10^{14} \mathrm{~F} \mathrm{~cm}^{-1}\right), \mu$ is the electron mobility, $L$ is the ETL thickness, and $V$ is the potential across the device $\left(V=V_{\text {applied }}-V_{\mathrm{bi}}-V_{\mathrm{r}}\right.$, where $V_{\mathrm{bi}}$ and $V_{\mathrm{r}}$ are the voltage drops induced by the built-in potential and the series resistance, respectively).

For the contact-angle measurements of the ETL films, the Phoenix-150 (SEO) analyzer 
was utilized. The Wu model was used to estimate the surface tensions of the ETLs based on the contact angles from both the water and glycerol (GC) droplets on the films. The detailed calculation procedures are expressed in the following equations:

$$
\begin{gathered}
\gamma_{\text {water }}\left(1+\cos \theta_{\text {water }}\right)=\frac{4 \gamma_{\text {water }}^{\mathrm{d}} \gamma^{\mathrm{d}}}{4 \gamma_{\text {water }}^{\mathrm{d}}+4 \gamma^{\mathrm{d}}}+\frac{4 \gamma_{\text {water }}^{\mathrm{p}} \gamma^{\mathrm{p}}}{4 \gamma_{\text {water }}^{\mathrm{p}}+4 \gamma^{\mathrm{p}}} \\
\gamma_{\mathrm{GC}}\left(1+\cos \theta_{\mathrm{GC}}\right)=\frac{4 \gamma_{\mathrm{GC}}^{\mathrm{d}} \gamma^{\mathrm{d}}}{4 \gamma_{\mathrm{GC}}^{\mathrm{d}}+4 \gamma^{\mathrm{d}}}+\frac{4 \gamma_{\mathrm{GC}}^{\mathrm{p}} \gamma^{\mathrm{p}}}{4 \gamma_{\mathrm{GC}}^{\mathrm{p}}+4 \gamma^{\mathrm{p}}} \\
\gamma_{\text {total }}=\gamma^{\mathrm{d}}+\gamma^{\mathrm{p}}
\end{gathered}
$$

where $\gamma_{\text {total }}$ is the total surface tension of each film, $\gamma^{\mathrm{d}}$ and $\gamma^{\mathrm{p}}$ are the dispersion and polar components of $\gamma_{\text {total }}$, respectively, and $\theta$ is the contact angle of the water or GC droplets on the films.

The active area of the OSC devices was $0.164 \mathrm{~cm}^{2}$, which was determined by OM. The $J-V$ properties of the OSCs were acquired using the AM $1.5 \mathrm{G}$ solar irradiation $\left(100 \mathrm{~mW} \mathrm{~cm} \mathrm{~cm}^{-2}\right)$ under ambient conditions. The solar simulator (K201 LAB55, McScience) satisfies Class AAA for the ASTM standards. The solar simulator was stabilized for more than 30 min after turning the lamp on. Then, the light intensity of the solar simulator was calibrated right before the PCE measurements by using a standard silicon reference cell, K801S-K302 (McScience). The $J-V$ curves were obtained using Keithley 2400 SMU. For the external quantum efficiency (EQE) measurement, a spectral measurement system, K3100 IQX (McScience), was used. The monochromatic light from a Xenon arc lamp $(300 \mathrm{~W})$ was filtered by an optical chopper (MC 2000 Thor labs) and a monochromator (Newport). The calculated $J_{\text {sc }}$ values were determined via integration of the product of the AM $1.5 \mathrm{G}$ solar spectrum and the EQE values. 


\section{Supplementary Figures and Tables}

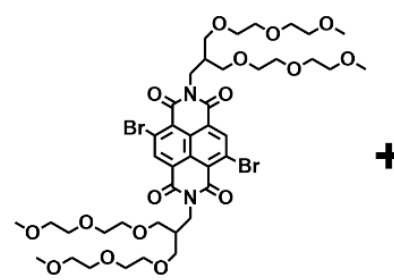

Monomer 1

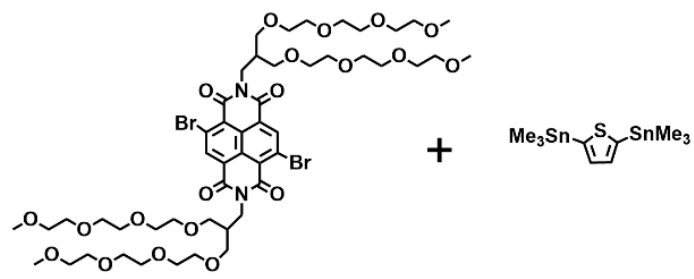

Monomer 2
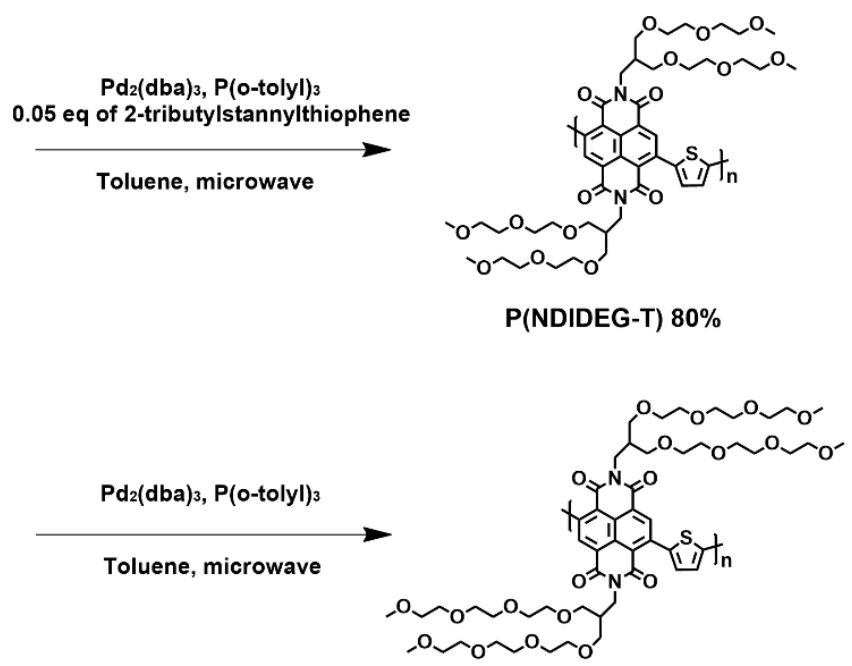

P(NDITEG-T) $81 \%$

Scheme S1. Synthetic routes for P(NDIDEG-T) and P(NDITEG-T) polymers. 


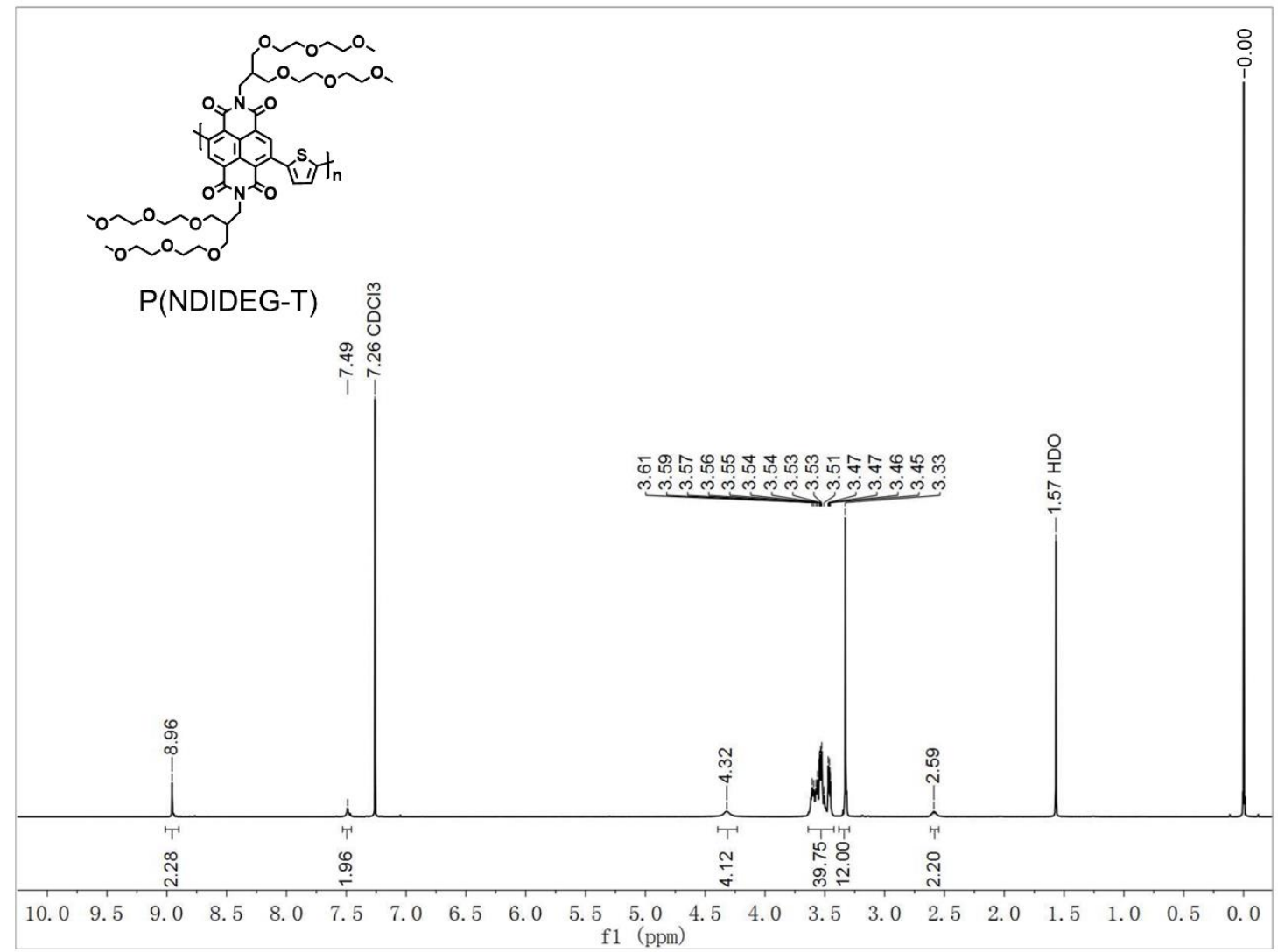

Figure S1. ${ }^{1} \mathrm{H}$ NMR spectrum of $\mathrm{P}(\mathrm{NDIDEG}-\mathrm{T})$ polymer. 


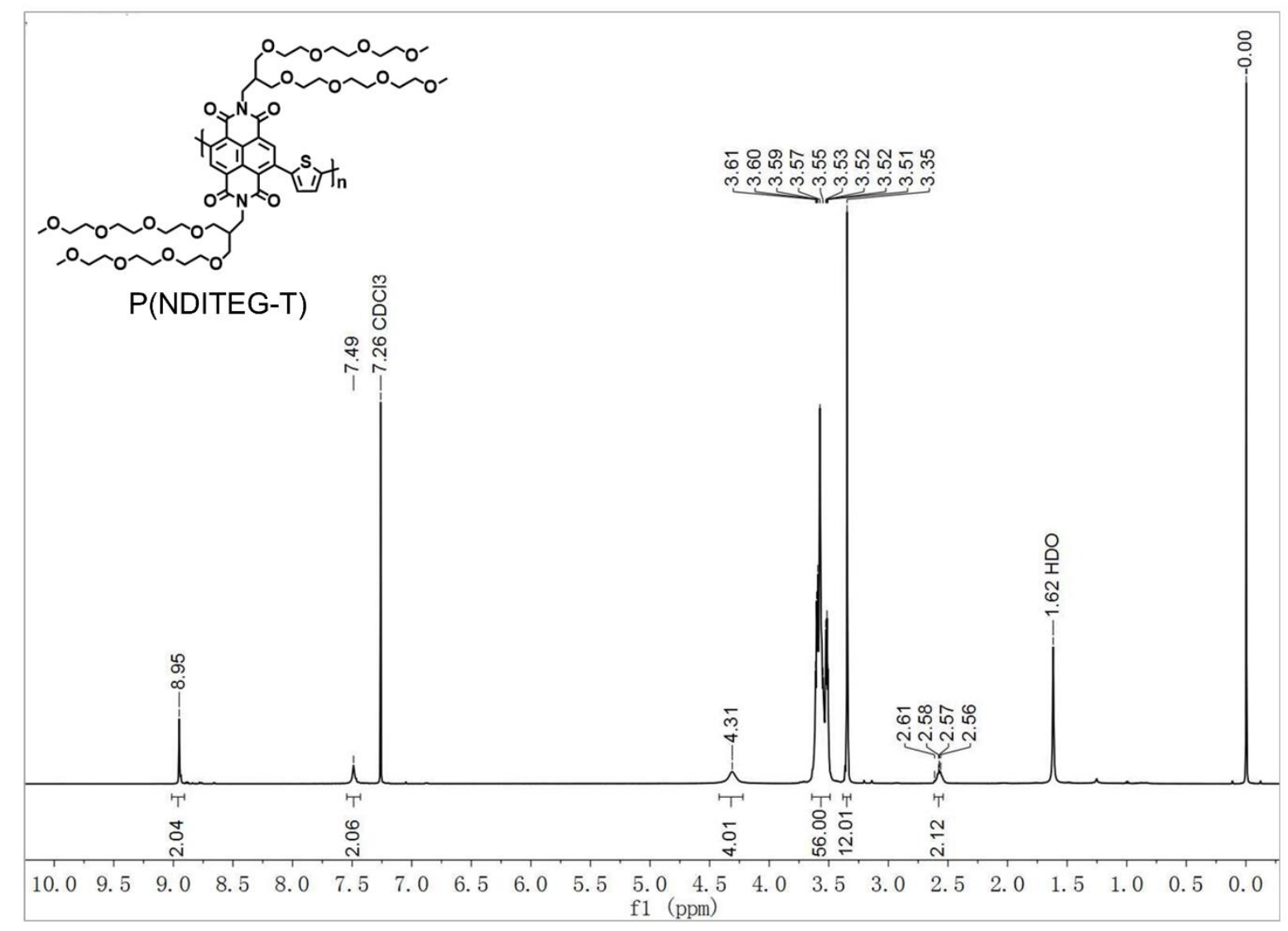

Figure S2. ${ }^{1} \mathrm{H}$ NMR spectrum of $\mathrm{P}(\mathrm{NDITEG}-\mathrm{T})$ polymer. 


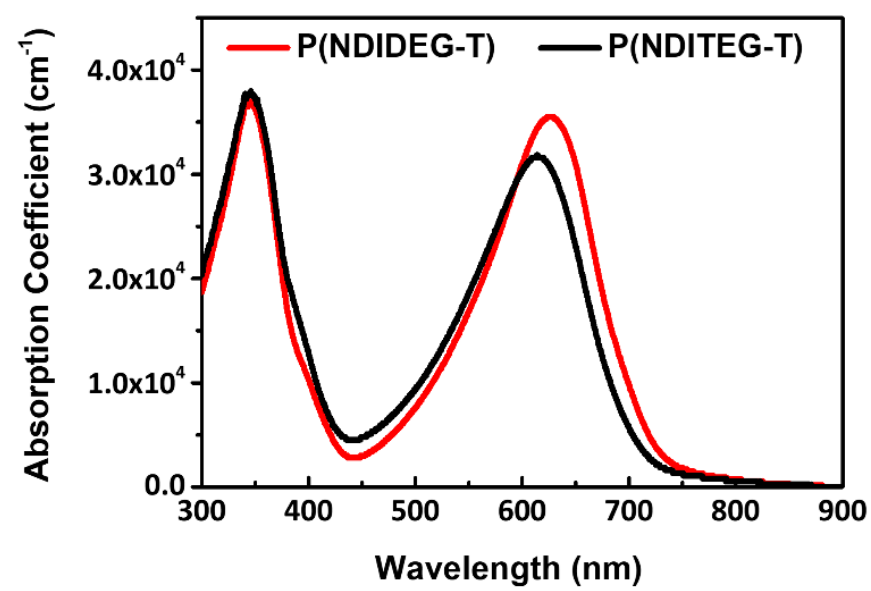

Figure S3. Absorption coefficients of P(NDIDEG-T) and P(NDITEG-T) polymers.

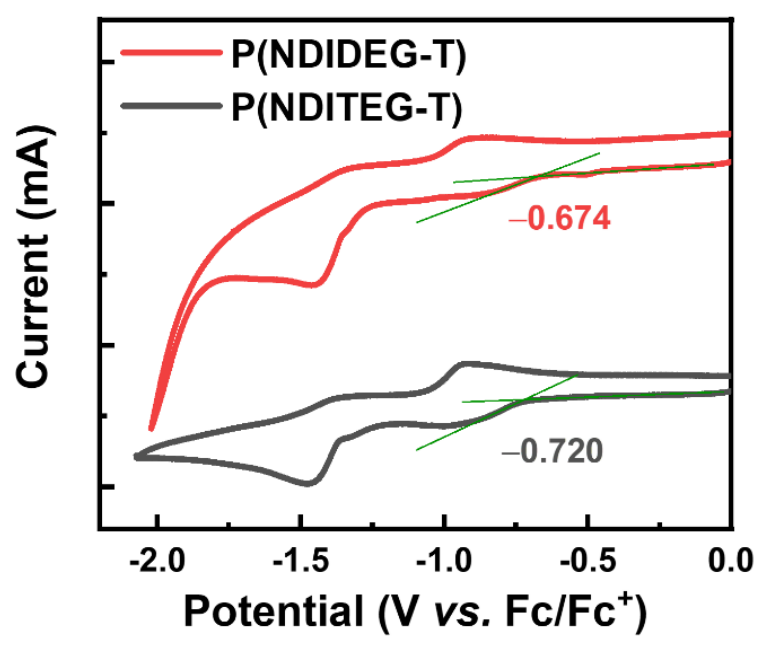

Figure S4. CV curves of P(NDIDEG-T) and P(NDITEG-T) polymers. 


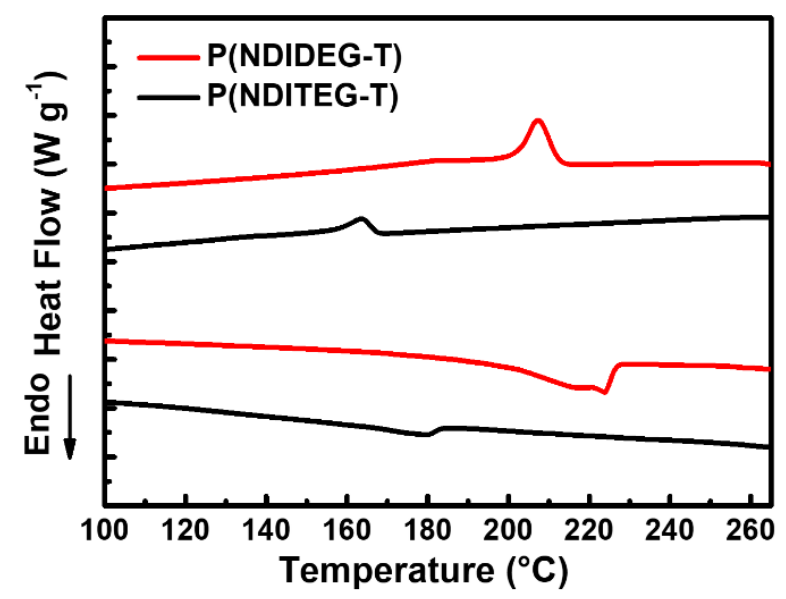

Figure S5. DSC thermograms of $\mathrm{P}(\mathrm{NDIDEG}-\mathrm{T})$ and $\mathrm{P}(\mathrm{NDITEG}-\mathrm{T})$ polymers.

Table S1. Melting temperature $\left(T_{\mathrm{m}}\right)$, crystallization temperature $\left(T_{\mathrm{c}}\right)$, and melting enthalpy $\left(\Delta H_{\mathrm{m}}\right)$ of $\mathrm{P}(\mathrm{NDIDEG}-\mathrm{T})$ and $\mathrm{P}(\mathrm{NDITEG}-\mathrm{T})$ polymers.

\begin{tabular}{cccc}
\hline Polymer & $\begin{array}{c}T_{\mathrm{m}} \\
\left({ }^{\circ} \mathrm{C}\right)\end{array}$ & $\begin{array}{c}T_{\mathrm{c}} \\
\left({ }^{\circ} \mathrm{C}\right)\end{array}$ & $\begin{array}{c}\Delta H_{\mathrm{m}} \\
\left(\mathrm{J} \mathrm{g}^{-1}\right)\end{array}$ \\
\hline P(NDIDEG-T) & 223 & 207 & 8.71 \\
P(NDITEG-T) & 176 & 163 & 2.31 \\
\hline
\end{tabular}

Table S2. Crystalline properties of P(NDIDEG-T) and P(NDITEG-T) polymer films obtained from the GIXS measurements.

\begin{tabular}{ccc|c}
\hline \multirow{2}{*}{ Polymer } & \multicolumn{2}{c|}{ In-plane (IP) } & Out-of-plane (OOP) \\
\cline { 2 - 4 } & $d_{001}(\AA)$ & $L_{\mathrm{c}, 001}(\mathrm{~nm})$ & $d_{010}(\AA)$ \\
\hline P(NDIDEG-T) & 10.1 & 11.3 & 3.89 \\
P(NDITEG-T) & 10.0 & 8.3 & 4.04 \\
\hline
\end{tabular}


(a)
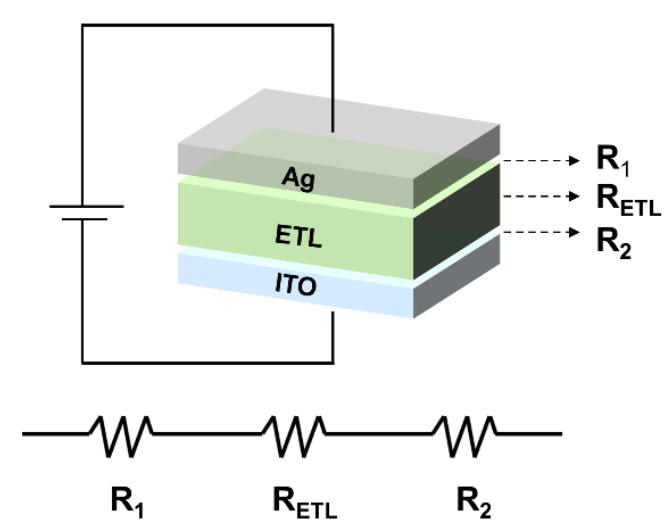

$$
\begin{aligned}
R & =R_{1}+R_{2}+R_{E T L} & & R: \text { resistance } \\
& =R_{1}+R_{2}+(\rho / A) d & & \rho \text { : resistivity }
\end{aligned}
$$

(b)

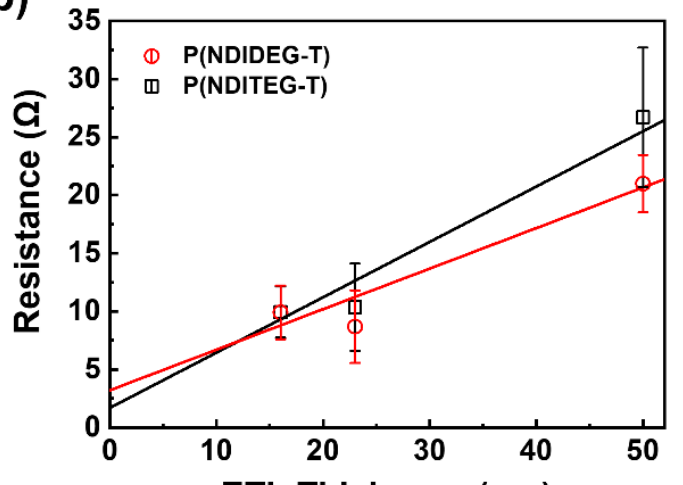

ETL Thickness (nm)

$$
\begin{aligned}
& \text { Linear-fitted equations } \\
& \text { P(NDIDEG-T): } y=0.34893 x+3.21327 \\
& P(\text { NDITEG-T }): y=0.47614 x+1.69467
\end{aligned}
$$

Figure S6. (a) Experimental set-up for the conductivity measurements and the corresponding equations. (b) Plot of resistance as a function of ETL thickness, and the linear-fitted equations for P(NDIDEG-T) and P(NDITEG-T). 


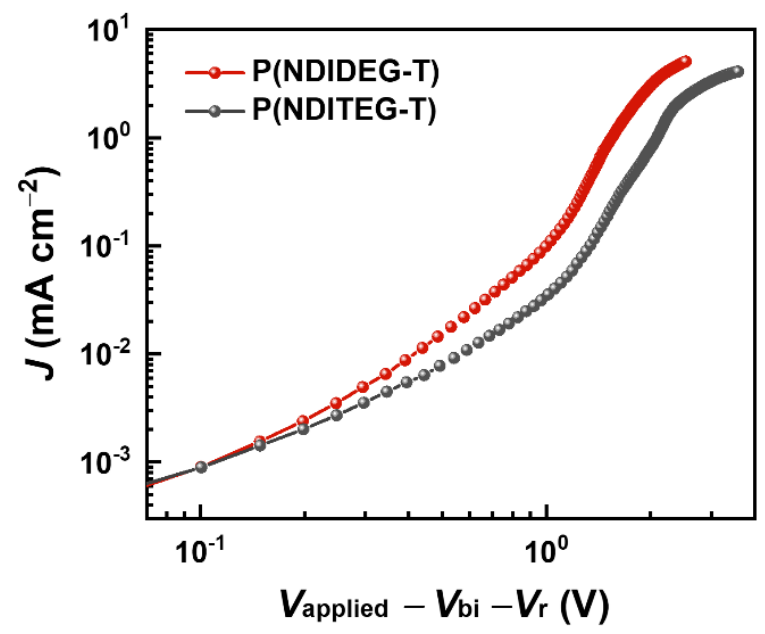

Figure S7. $J-V$ curves of electron-only devices based on P(NDIDEG-T) and P(NDITEG-T).

Table S3. Electron mobility $\left(\mu_{\mathrm{e}}\right)$ values of the $\mathrm{P}(\mathrm{NDIDEG}-\mathrm{T})$ and $\mathrm{P}(\mathrm{NDITEG}-\mathrm{T})$ pristine films.

\begin{tabular}{ccc}
\hline Material & $\begin{array}{c}\mu_{\mathrm{e}, \text { avg }}{ }^{a} \\
\left(\mathrm{~cm}^{2} \mathrm{~V}^{-1} \mathrm{~s}^{-1}\right)\end{array}$ & $\begin{array}{c}\mu_{\mathrm{e}, \max } \\
\left(\mathrm{cm}^{2} \mathrm{~V}^{-1} \mathrm{~s}^{-1}\right)\end{array}$ \\
\hline $\mathrm{P}($ NDIDEG-T $)$ & $(3.9 \pm 0.7) \times 10^{-5}$ & $4.7 \times 10^{-5}$ \\
$\mathrm{P}($ NDITEG-T $)$ & $(1.4 \pm 0.8) \times 10^{-5}$ & $2.5 \times 10^{-5}$
\end{tabular}

${ }^{a}$ Average values were obtained from at least five different devices. 
(a)

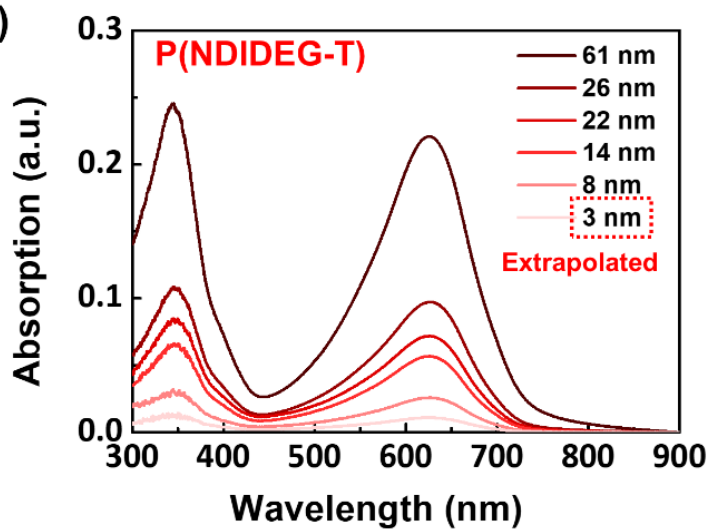

(b)

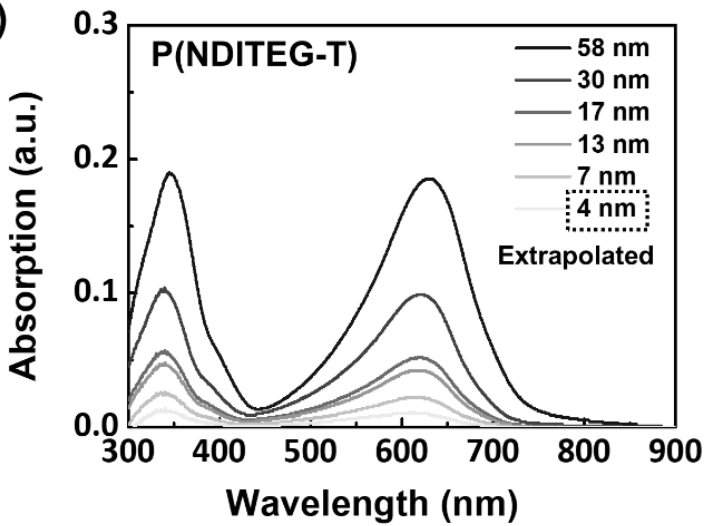

(c)

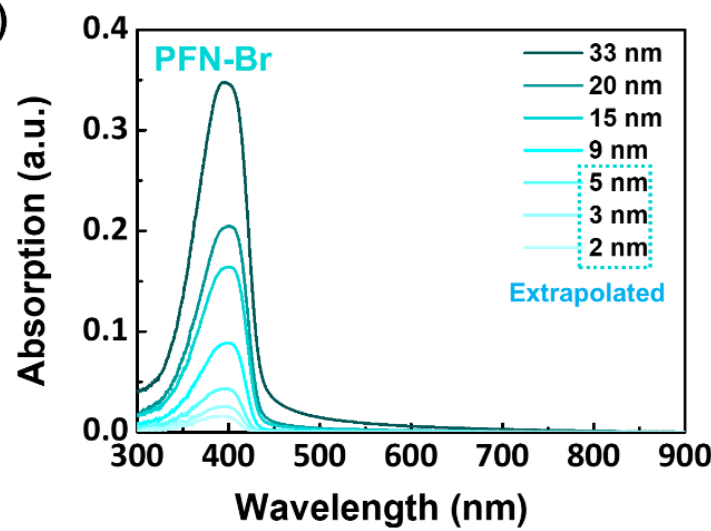

(d)
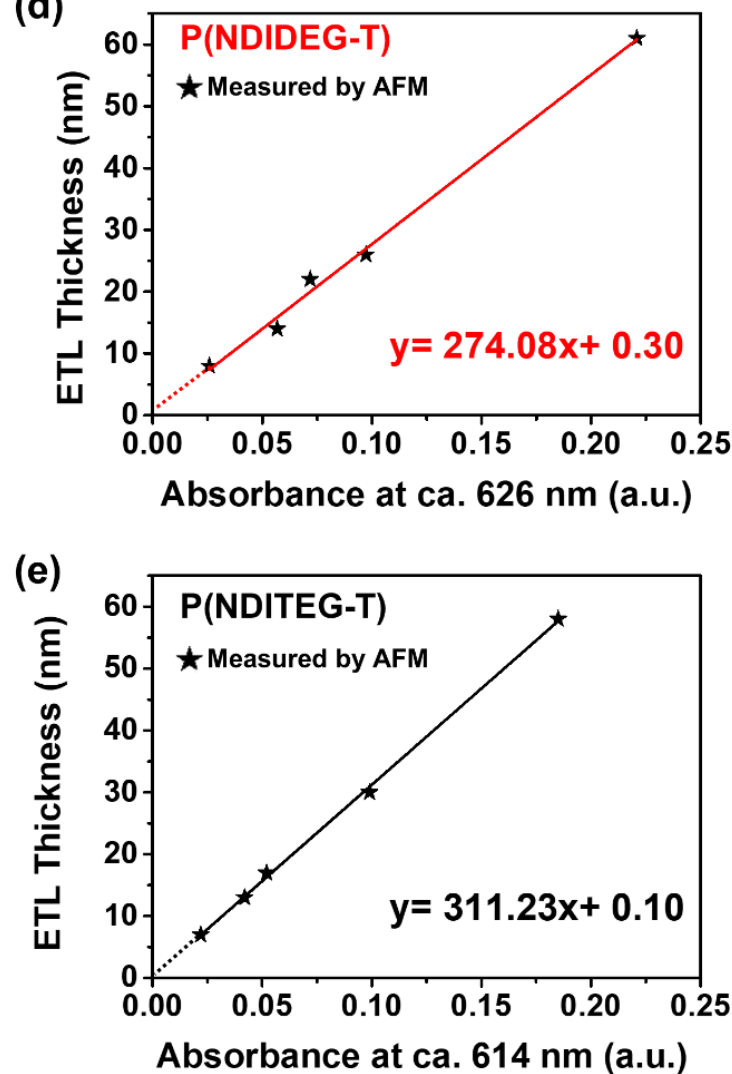

(f)

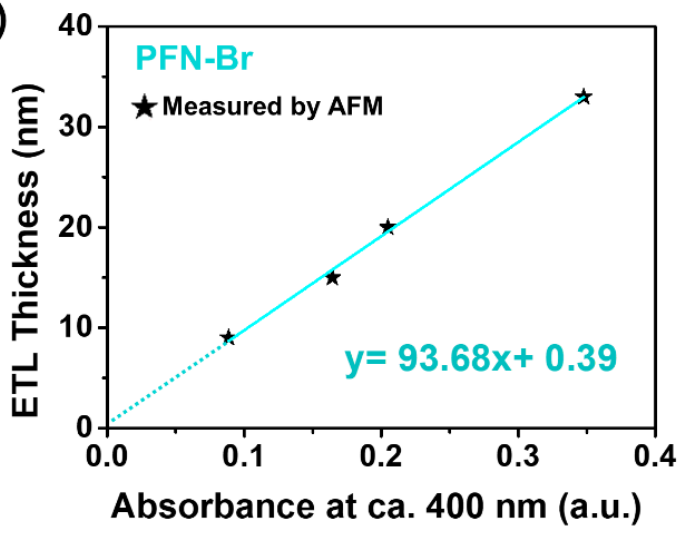

Figure S8. $(\mathrm{a}, \mathrm{b}, \mathrm{c}) \mathrm{UV}-\mathrm{V}$ is absorption spectra of $\mathrm{P}(\mathrm{NDIDEG}-\mathrm{T}), \mathrm{P}(\mathrm{NDITEG}-\mathrm{T})$, and PFN-Br films with various thicknesses. (d, e, f) Extrapolation lines constructed from the absorptionthickness relationship of each ETL film. 